\title{
ANALIZA NARAŻEŃ UKŁADÓW IZOLACYJNCYH TRANSFORMATORÓW OD PRZEPIĘĆ LĄCZENIOWYCH
}

\author{
Piotr Pająk \\ Akademia Górniczo-Hutnicza, Katedra Elektrotechniki i Elektroenergetyki
}

Streszczenie. Intensywny rozwój taczników próżniowych, zastosowanie próżni jako elementu gaszacego, jak również postęp w dziedzinie materiałów stykowych przyczynity się do szerokiego zastosowania wylączników próżniowych $w$ energetyce. Wyłaczniki te wykazuja jednak pewne niekorzystne właściwości, które maja wpływ na przepięcia pojawiające się na łączonych obiektach. W artykule przedstawiono wyniki symulacji oraz wyniki badań przepięć generowanych podczas wyłaczania transformatorów przy użyciu wyłączników próżniowych. Dokonano również analizy wplywu ograniczników przepięć.

Słowa kluczowe: przepięcia łączeniowe, wyłącznik próżniowy, model matematyczny

\section{ANALYSIS OF INSULATION TRANSFORMERS SYSTEM RISKS FROM SWITCHING OVERVOLTAGES}

\begin{abstract}
Intensive devlopment in the area of vacuum switches, usage of vacuum as a extinguishing element, as well as progress in the area of contact materials contributed to broad usage of vacuum circuit breakers in energetics. However, vacuum cicuit breakers show adverse characteristics that affect switching surge waveforms, which appear on switching objects. The article presents results of computer simulations and test results of overvoltages generated during switching off by vacuum circuit breakers. Influence of metal oxide surge arresters will be also presented.
\end{abstract}

Keywords: switching overvoltages, vacuum circuit breakers, mathematical model

\section{Wstęp}

Coraz częściej w sieciach rozdzielczych średniego napięcia w celu przeprowadzenia łączeń urządzeń elektroenergetycznych, wykorzystywane są wyłączniki, w których medium gaszącym jest próżnia. Ten rodzaj wyłączników jest powszechnie stosowany w zakresie średnich napięć, a jego udział w europejskim rynku wszystkich łączników elektroenergetycznych cały czas rośnie. Dzieje się tak ze względu na szereg zalet, które wyróżniają go na tle innych rodzajów wyłączników. Są to m.in.: duża zdolność łączeniowa, zdolność wyłączania prądów o dużej częstotliwości, szybki wzrost wytrzymałości powrotnej jak również bezpieczeństwo oraz tania eksploatacja. $\mathrm{Z}$ zastosowaniem wyłączników próżniowych wiążą się również pewne problemy. Moment, w którym następuje otwarcie wyłącznika nie jest kontrolowany, co sprawia, że duże wartości przepięć mogą się pojawić w chwili, gdy prąd zostanie ucięty przed jego naturalnym przejściem przez zero. Prowadzi to do powstawania znacznych przepięć podczas łączenia obwodów o charakterze indukcyjnym. Decydujący wpływ na te przepięcia mają zjawiska zachodzące w komorach gaszeniowych wyłącznika podczas rozchodzenia się jego styków. Dlatego też, równocześnie z rozwojem tego rodzaju wyłączników, prowadzone są badania zjawisk zachodzących w komorach próżniowych, towarzyszących czynnościom łączeniowym, które mają decydujący wpływ na przebiegi napięć i prądów w łączonych obwodach [6 - 8]. Badania te mają na celu określenie charakteru przepięć, wyznaczenie wartości maksymalnych, jak również określenie skuteczności ochrony obecnie stosowanych metod przeciwprzepięciowych.

W artykule przeprowadzono analizę przepięć narażających układ izolacyjny transformatora średniego napięcia podczas czynności łączeniowych. Podstawą analizy były wyniki symulacji oraz wyniki badań przepięć w układzie stanowiącym fragment sieci średniego napięcia.

\section{Stany przejściowe napięć i prądów podczas lączeń wylącznikiem próżniowym}

Bezpośrednio po zainicjowaniu rozchodzenia się styków wyłącznika, wartość prądu wzrasta do wartości określonej przez prąd ucięcia. Po ucięciu prądu (pkt. A na rys. 1), pomiędzy stykami wyłącznika pojawia się przejściowe napięcie powrotne, które zależy od parametrów układu. Od momentu, w którym nastąpiło zainicjowanie rozchodzenia się styków wyłącznika, w wyniku zwiększania się odległości pomiędzy nimi, wzrasta wytrzymałość dielektryczna przerwy międzystykowej $\left(U_{w y}\right)$. $\mathrm{W}$ chwili, gdy napięcie powrotne pojawiające się na zaciskach wyłącznika przewyższa wytrzymałość chwilową przerwy pomiędzy stykami wyłącznika (pkt. B na rys. 1), dochodzi do ponownego przeskoku łuku pomiędzy stykami i przez szczelinę wyłącznika zaczyna płynąć prąd.

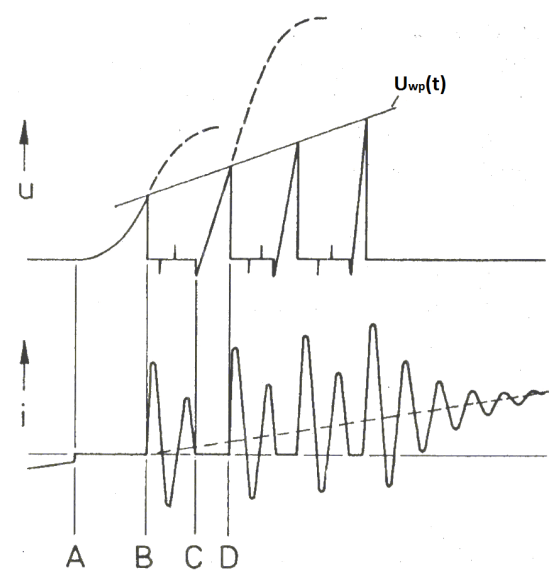

Rys. 1. Przebiegi napięcia oraz pradu podczas taczeń przy użyciu wyłacznika próżniowego [1]

Ze względu na bardzo dużą częstotliwość, jest on szybko thumiony, ale nie gaśnie w naturalny sposób przy pierwszym przejściu przez zero. Przerwanie tego prądu następuje w chwili gdy jego wartość będzie mniejsza niż graniczna wartość prądu, która ściśle zależy od właściwości wyłącznika próżniowego (pkt. C na rys. 1). Kolejne powtórne przeskoki napięcia wystapią, jeżeli wartość chwilowa $\mathrm{w}$ dalszym ciągu będzie przekraczać wytrzymałość elektryczną wyłącznika (pkt. D na rys. 1). Ostatecznie prąd jest przerwany, a odległość między stykami wyłącznika jest dostatecznie duża, aby wytrzymać napięcie powrotne.

\section{Model cyfrowy wyłącznika próżniowego}

Aby stworzyć model wyłącznika próżniowego, który w pełni odwzoruje zjawisko przeskoków powtórnych, należy wziąć pod uwagę trzy podstawowe zagadnienia: wartość prądu ucięcia, wytrzymałość elektryczną przerwy międzystykowej oraz zdolność gaszenia prądów o dużej częstotliwości.

W tym celu zastosowano program komputerowy Electromagnetic Transients Program - Alternative Transients Program (EMTP/ATP) [4]. Model wyłącznika próżniowego, uwzględniający zjawiska zachodzące $\mathrm{w}$ komorze próżniowej podczas wyłączania urządzeń, przedstawiono na rysunku 2. 


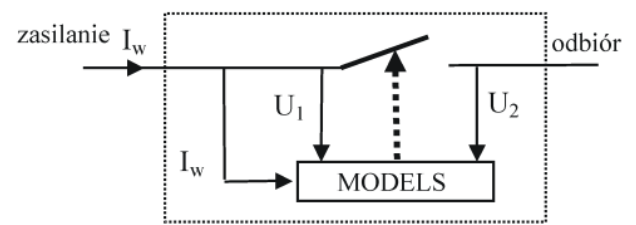

Rys. 2. Model wyłącznika próżniowego

Sposób, w jaki odbywa się sterowanie wyłącznikiem, został zaprezentowany przy pomocy algorytmu na rysunku 3.

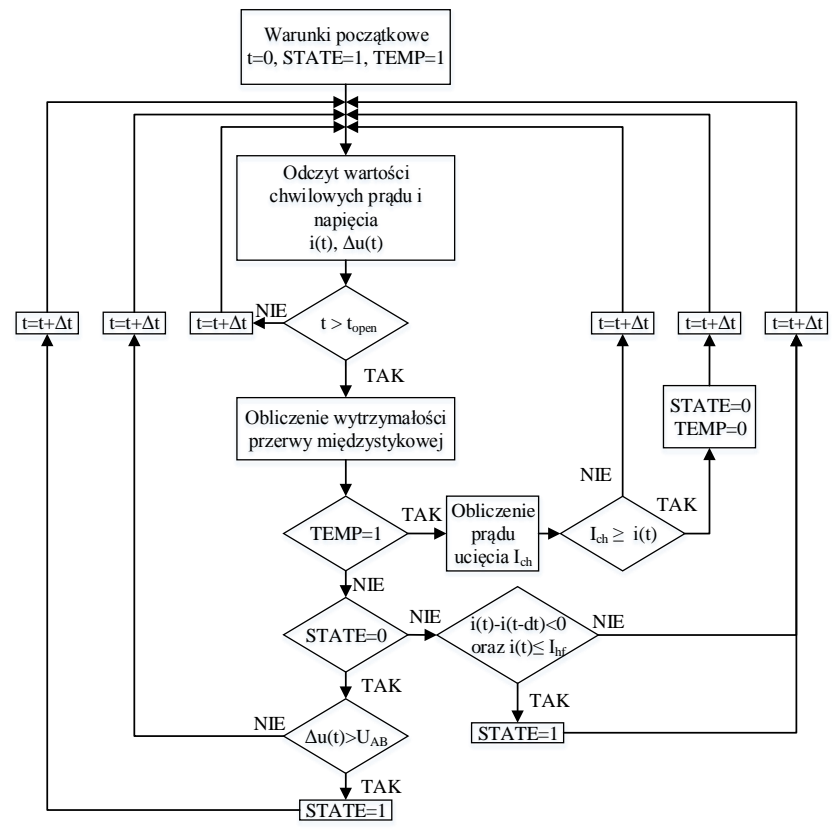

Rys. 3. Algorytm sterujacy idealnym wylacznikiem

Zastosowany model ma postać idealnego wyłącznika. W każdym kroku obliczeń kontrolowane jest napięcie na wyłączniku, które jest porównywane z aktualną wytrzymałością dielektryczną wyłącznika. Wyłącznik zamyka się wówczas, gdy wartość tego napięcia przekracza wartość chwilowej wytrzymałości elektrycznej przerwy pomiędzy stykami wyłącznika. Otwierany jest w chwili, kiedy prąd przepływający po zamknięciu będzie mniejszy od wartości zadanej, wynikającej ze zdolności do wyłączania prądów wysokiej częstotliwości przez wyłączniki próżniowe.

Mechanizm, który kontroluje pracę wyłącznika został zaprogramowany przy użyciu języka programowania MODELS, będącego wewnętrznym środowiskiem programowania EMTP-ATP.

Zastosowany model wyłącznika próżniowego uwzględnia prąd ucięcia wyłącznika o częstotliwości $50 \mathrm{~Hz}$. Wartość prądu ucięcia została wyznaczona na podstawie zależności:

$$
I_{c h}=(2 \pi \mathrm{f} \text { i } \alpha \beta)^{q}
$$

gdzie: f - częstotliwość źródła zasilania, i - natężenie prądu $50 \mathrm{~Hz}$, współczynniki $\alpha=6,2 \cdot 10-16 \mathrm{~s}, \quad \beta=14,3, \quad q=-0.07512$ $[3,5]$.

Wartości prądów wyznaczone na podstawie wyrażenia (1) odpowiadają prądom ucięcia $\mathrm{w}$ wyłącznikach próżniowych ze stykami miedziowo-chromowymi. Istotny wpływ na przepięcia ma również prędkość otwarcia wyłącznika. Szybkość narastania wytrzymałości powrotnej pomiędzy stykami wyłącznika ściśle zależy od prędkości rozchodzenia się jego styków. W większości nowoczesnych wyłączników można założyć, że prędkość rozchodzenia się styków jest stała, co powoduje, że odległość pomiędzy stykami zwiększa się liniowo.
W związku $\mathrm{z}$ tym, w przedstawionym modelu, napięcie wytrzymywane przerwy międzystykowej wyłącznika uzależniono liniowo od odległości pomiędzy stykami i zapisano wzorem:

$$
U_{d}=E_{k r} v t
$$

gdzie: $E_{k r}$ - wytrzymywane natężenie pola elektrycznego między stykami, $v$ - prędkość rozłączania styków, $t$ - czas symulacji [1]

Podczas obliczeń przepięć łączeniowych ograniczniki przepięć z tlenków metali, stosowane do ochrony przepięciowej transformatora, zastąpiono modelem przedstawionym na rysunku 4 [5].

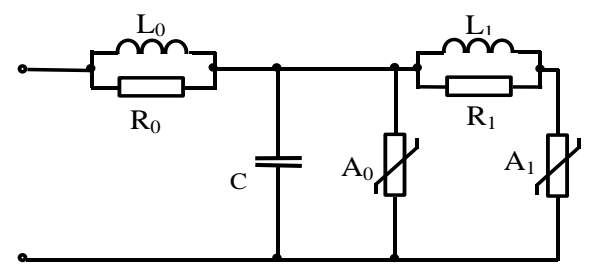

Rys. 4. Schemat zastępczy ograniczników przepięć z tlenków metali

Modele linii łączących wykonano przy pomocy procedury JMARTI. Do zamodelowania transformatora zastosowano procedurę SATURABLE.

\section{Charakterystyka układu doświadczalnego}

Schemat układu pomiarowego, stanowiący fragment sieci średniego napięcia, przedstawiono na rysunku 5. Stanowisko jest zasilane $\mathrm{z}$ sieci nn przy zastosowaniu transformatora $\operatorname{Tr}_{l}$. Transformator doświadczalny $\operatorname{Tr}_{2}$ jest połączony $\mathrm{z}$ wyłącznikiem próżniowym $W$ za pomocą linii kablowej $\mathrm{L}_{2}$ o długości $85 \mathrm{~m}$. Transformator doświadczalny pracuje na biegu jałowym. Przebiegi napięć na zaciskach transformatora $T r_{2}$ są rejestrowane za pomocą sond wysokonapięciowych połączonych $\mathrm{z}$ oscyloskopem cyfrowym firmy Tektronix, który współpracuje z komputerem przy pomocy karty pomiarowej NI-GPIB-USB-HS.

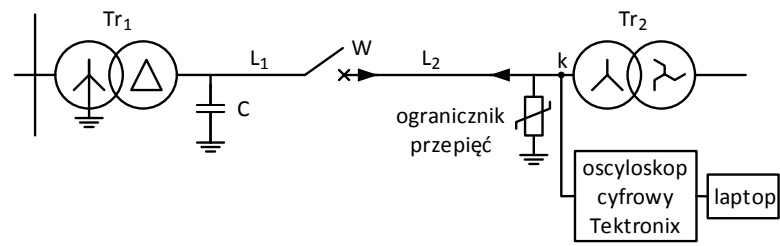

Rys. 5. Schemat uktadu do badań przepięć taczeniowych $w$ transformatorze: $\mathrm{Tr}_{1}$ - transformator zasilajacy typu TNOSCT-250/15.75PNS, $L_{1}-$ szynoprzewody o dlugości $2 m, L_{2}$ - linia kablowa, W - wyłacznik próżniowy, $T_{2}$ - transformator doświadczalny typu TOC 20/10, C - bateria kondensatorów, $k$ - punkt rejestracji przepięć

Podstawowe parametry elektryczne urządzeń zamieszczono w tabelach o numerach od 1 do 5 .

Tabela 1. Podstawowe parametry transformatorów stosowanych $w$ stanowisku doświadczalnym

\begin{tabular}{|c|c|c|}
\hline parametr/typ & TNOSCT-250/15.75PNS & TOC 20/10 \\
\hline$S_{n}, \mathrm{kVA}$ & 250 & 20 \\
\hline$U_{n}, \mathrm{kV}$ & $15,75 / 0,4$ & $6 / 0,4$ \\
\hline$U_{z}, \%$ & 4,5 & 4,29 \\
\hline$\Delta P_{F e}, \mathrm{~kW}$ & 0,486 & 0,02 \\
\hline$\Delta P_{C u}, \mathrm{~kW}$ & 3,509 & 0,22 \\
\hline$I_{0}, \%$ & 1,0 & 0,54 \\
\hline
\end{tabular}


Tabela 2. Parametry wyłącznika próżniowego typu VD4

\begin{tabular}{|c|c|c|}
\hline parametr & jednostka & wartość \\
\hline napięcie znamionowe & $\mathrm{kV}$ & 12 \\
\hline wytrzymywane natężenie pola elektrycznego & $\mathrm{kV} \mathrm{mm}^{-1}$ & 12 \\
\hline szybkość rozchodzenia się styków & $\mathrm{m} \mathrm{s}^{-1}$ & 1 \\
\hline maksymalny odstęp pomiędzy stykami & $\mathrm{mm}$ & 5 \\
\hline prąd ucięcia wielkiej częstotliwości & $\mathrm{A}$ & 0,125 \\
\hline
\end{tabular}

Tabela 3. Napięcia obniżone ograniczników przepięć z tlenków metali typu POLIM-D 7,5 [8]

\begin{tabular}{|c|c|c|c|c|c|c|c|}
\hline \multirow{4}{*}{$\begin{array}{c}\text { typ } \\
\text { ogranicznika }\end{array}$} & \multirow{3}{*}{$U_{n}$} & \multirow{3}{*}{$U_{c}$} & \multicolumn{5}{|c|}{ napięcie obniżone przy udarach prądowych } \\
\hline & & & \multicolumn{3}{|c|}{$8 / 20 \mu \mathrm{s}$} & \multicolumn{2}{|c|}{$30 / 60 \mu \mathrm{s}$} \\
\hline & & & $5 \mathrm{kA}$ & $10 \mathrm{kA}$ & $20 \mathrm{kA}$ & $0,5 \mathrm{kA}$ & $2 \mathrm{kA}$ \\
\hline & \multicolumn{7}{|c|}{$\mathrm{kV}$} \\
\hline POLIM-D & 7,5 & 6 & 19,6 & 21,0 & 23,9 & 16,6 & 18,2 \\
\hline
\end{tabular}

Do ochrony transformatora od przepięć zastosowano beziskiernikowe ograniczniki przepięć $\mathrm{z}$ tlenków metali typu POLIM-D. Parametry ograniczników przepięć, o napięciu znamionowym $7,5 \mathrm{kV}$, stosowanych w sieciach $6 \mathrm{kV}$ z uziemionym punktem neutralnym przez rezystor lub cewkę, przedstawiono w tabeli 3. Zależność dynamiczną u=f(i) dla udaru $8 / 20 \mu$ s tych ograniczników, wyznaczoną przy zastosowaniu schematu ograniczników pokazanego na rysunku 4, przedstawiono na rysunku 6.

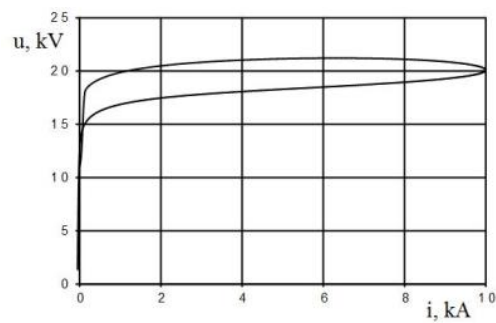

Rys. 6. Zależność dynamiczna napięciowo-pradowa dla udaru prądowego $10 \mathrm{kA}$ $8 / 20 \mu$ s ogranicznika typu POLIM-D, wyznaczona przy zastosowaniu schematu zastępczego ograniczników (rys. 4)

Tabela 4. Parametry linii $L_{1} i L_{2}$

\begin{tabular}{|c|c|c|}
\hline Parametr/typ & Linia $\mathrm{L}_{1}$ & Linia $\mathrm{L}_{2}$ \\
\hline Oznaczenie & Drut miedziany & RG 213U MIL.C 17/D \\
\hline Długość $[\mathrm{m}]$ & 2 & 85 \\
\hline Impedancja $[\Omega]$ & - & 50 \\
\hline Pojemność $\mathrm{C}[\mathrm{pF} / \mathrm{m}]$ & - & $98 \pm 3$ \\
\hline
\end{tabular}

Tabela 5. Parametry baterii kondensatorów

\begin{tabular}{|c|c|c|}
\hline Parametr & jednostka & wartość \\
\hline napięcie znamionowe $U_{N}$ & $\mathrm{kV}$ & 15 \\
\hline Pojemność $C_{N}$ & $\mu \mathrm{F} \pm 10 \%$ & 0,5 \\
\hline Częstotliwość $f$ & $\mathrm{~Hz}$ & 50 \\
\hline Temperatura pracy & ${ }^{\circ} \mathrm{C}$ & $-25 \div 50$ \\
\hline
\end{tabular}

\section{Wyniki symulacji komputerowych}

Przeprowadzone symulacje komputerowe polegały na wyznaczeniu wartości przepięć doziemnych, powstających na zaciskach transformatora $\operatorname{Tr} 2$ podczas wyłączeń transformatora pracującego na biegu jałowym. Przykładowe wyniki symulacji wykonane dla układu z zastosowaniem ograniczników przepięć,

a)

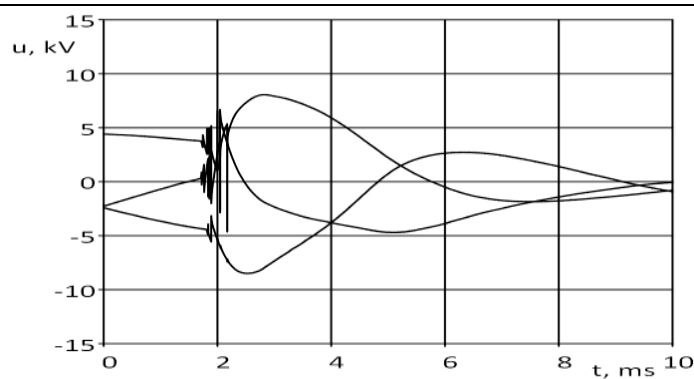

jak również przy braku ochrony przepięciowej, zostały przedstawione na rysunkach 7 i 8 .

Z obliczeń przebiegów przepięć, powstających podczas wyłączania transformatora wyłącznikami próżniowymi wynika, że układ izolacyjny transformatora podczas tego typu łączeń jest narażony na oddziaływanie przepięć o wartościach znacznie większych od wartości maksymalnych napięcia roboczego. Występujące wówczas przepięcia mają charakter oscylacyjny, wynikający $\mathrm{z}$ przeskoków pomiędzy stykami otwieranego wyłącznika próżniowego. Przeprowadzone obliczenia potwierdzają także, że ograniczniki przepięć z tlenków metali zmniejszają wartości maksymalne przepięć łączeniowych. Nie mają one jednak istotnego wpływu na zmianę przebiegów tych przepięć i nie powodują thumienia składowych oscylacyjnych przepięć. Skutkiem czego napięcie docierające do zacisków transformatora może być dodatkowo wzmacniane wewnątrz samych już uzwojeń tych transformatorów, dodatkowo narażając jego izolację [9].

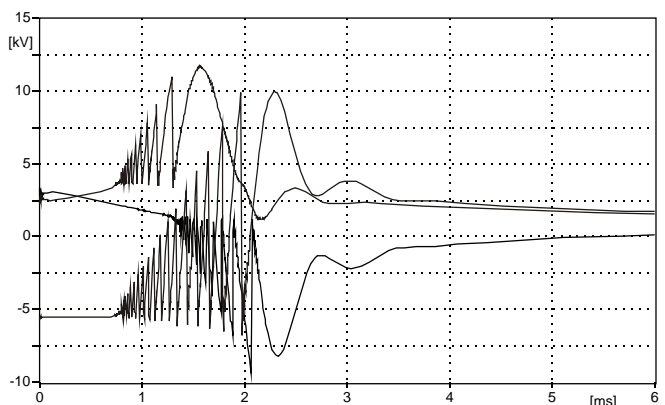

Rys. 7. Przebiegi teoretyczne przepięć na zaciskach wejściowych transformatora $\operatorname{Tr}_{2}$ (rys. 5) po jego wytaczeniu w uktadzie bez ochrony przepięciowej

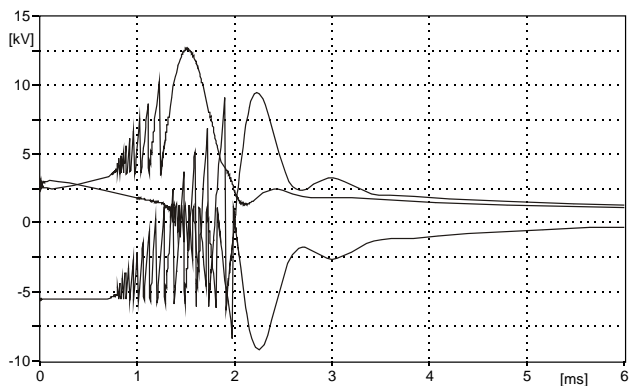

Rys. 8. Przebiegi teoretyczne przepięć na zaciskach wejściowych transformatora $\operatorname{Tr}_{2}$ (wg. rys. 5) po jego wytaczeniu w uktadzie z ochrona przepięciowa

\section{Wyniki badań laboratoryjnych}

Badania obejmowały rejestracje przepięć doziemnych, generowanych na zaciskach transformatora $\operatorname{Tr}_{2}$ podczas jego wyłączania.

Pomiary przeprowadzono $\mathrm{w}$ układzie stanowiącym fragment sieci średniego napięcia. Celem badań było wyznaczenie poziomów napięć narażających układ izolacyjny transformatora podczas wyłączania transformatora przy zastosowaniu wyłącznika próżniowego. Badania przepięć łączeniowych w transformatorach zostały wykonane dla czterech różnych przypadków układów połączeń. Otrzymane wyniki zostały zamieszczone na rys. $9-12$.

b)

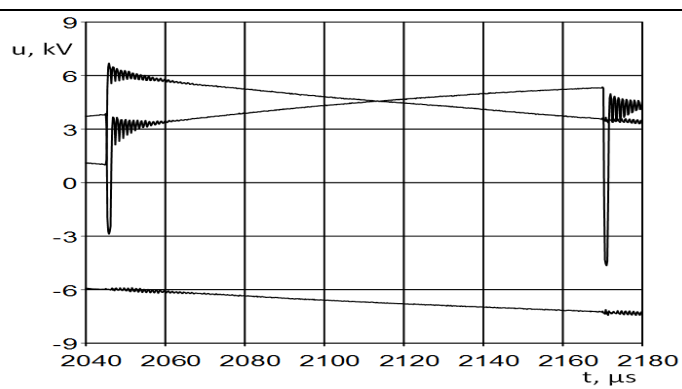

Rys. 9. Przebiegi doświadczalne przepięć doziemnych na zaciskach wejściowych transformatora średniego napięcia Tr 2 (rys. 5), wyłączanego przy zastosowaniu wyłacznika próżniowego. $a$ - przepięcia doziemne na zaciskach transformatora z ochrona przepięciowa, $b$-wybrany fragment przebiegu $z$ punktu a) w powiększeniu 
a)

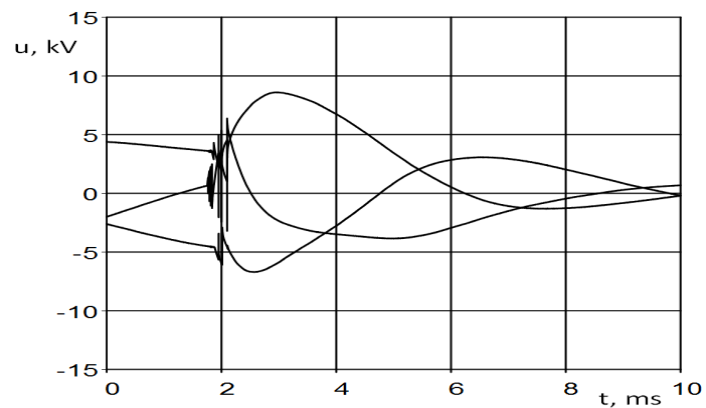

b)

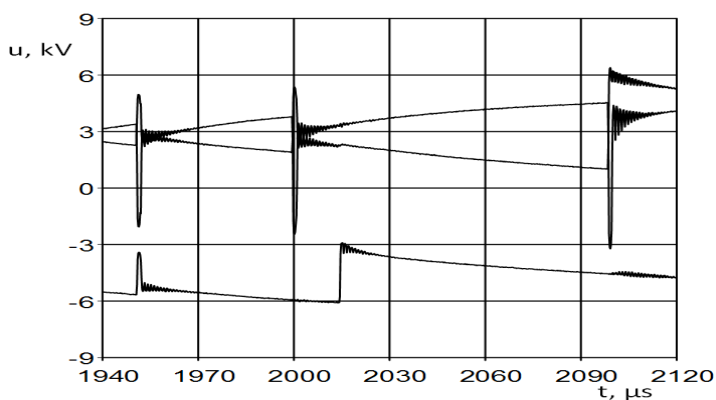

Rys. 10. Przebiegi doświadczalne przepięć doziemnych na zaciskach wejściowych transformatora średniego napięcia Tr 2 (rys. 5), wyłaczanego przy zastosowaniu wyłacznika próżniowego. a - przepięcia doziemne na zaciskach transformatora bez ochrony przepięciowej, $b$ - wybrany fragment przebiegu z punktu a) w powiększeniu

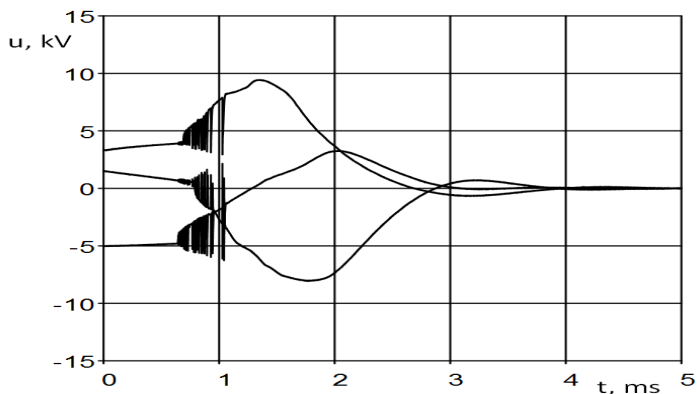

b)

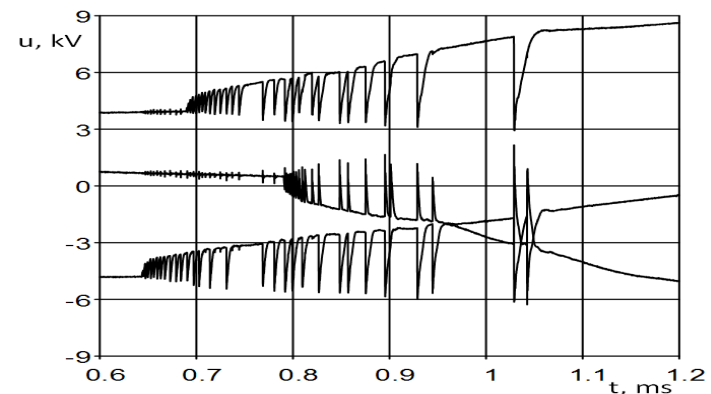

Rys. 11. Przebiegi doświadczalne przepięć doziemnych na zaciskach wejściowych transformatora średniego napięcia Tr. (rys. 5), wyłączanego przy zastosowaniu wyłącznika próżniowego. a-przepięcia doziemne na zaciskach transformatora zochrona przepięciowa, układ po zamianie miejscami linii $L_{1}$ oraz linii $L_{2}$ $b$ - wybrany fragment przebiegu z punktu a) w powiększeniu

a)

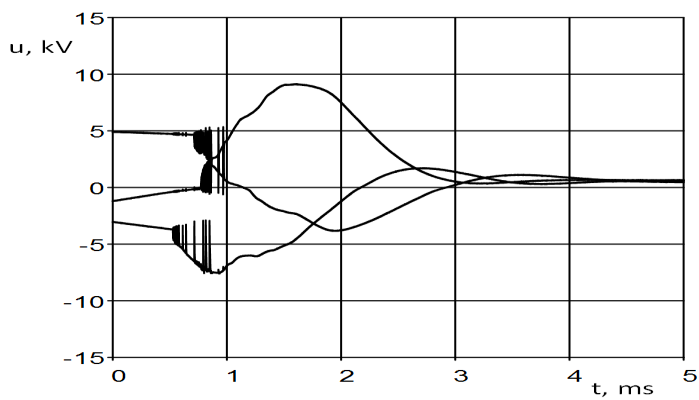

b)

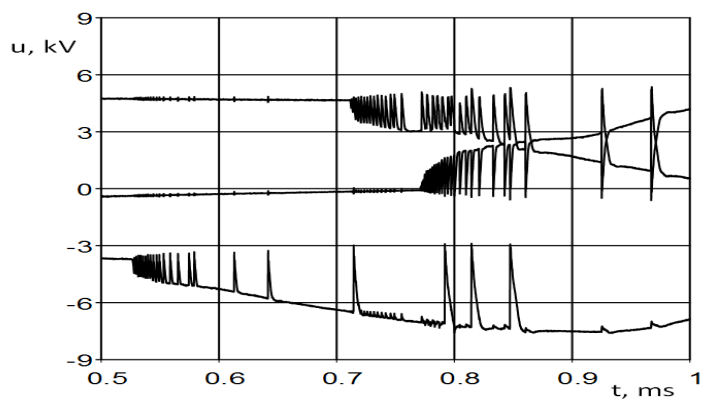

Rys. 12. Przebiegi doświadczalne przepięć doziemnych na zaciskach wejściowych transformatora średniego napięcia Tr. (rys. 5), wyłaczanego przy zastosowaniu wyłacznika próżniowego. a-przepięcia doziemne na zaciskach transformatora bez ochrony przepięciowej, układ po zamianie miejscami linii $L_{1}$ oraz linii $L_{2}$, $b$-wybrany fragment przebiegu z punktu a) w powiększeniu

\section{Podsumowanie}

Podczas wyłączania transformatorów wyłącznikami próżniowymi, następuje wzrost narażeń układów izolacyjnych od przepięć generowanych na zaciskach wejściowych uzwojeń. Wartości maksymalne przepięć powstających podczas wyłączania transformatorów są zależne od przebiegu zjawisk wewnątrz komór wyłączników oraz zjawisk przejściowych w układzie elektrycznym.

Symulacje przepięć łączeniowych, potwierdzaja że przedstawiony model wyłączników próżniowych umożliwia wyznaczanie przepięć generowanych podczas wyłączania urządzeń takimi wyłącznikami.

Wyniki badań pokazują również wpływ układu połączeń linii kablowej, na przebiegi napięć pojawiających się na zaciskach transformatora. Po zamianie miejscami linii $\mathrm{L}_{1} \mathrm{z}$ linią $\mathrm{L}_{2}$, zmianie ulega również kształt oraz częstotliwość przebiegów.

\section{Literatura}

[1] ATPDRAW v.3.5 for Windows 9x/NT/2000/XP User's Manual, 2002.

[2] Florkowski M., Furgał J., Pająk P.: Narażenia transformatorów od przepięć łączeniowych w układach elektroenergetycznych, Przegląd Elektrotechniczny. 86 n.5, 2010, s. 245-248.

[3] Helmer J., Lindmayer M.: Mathematical Modeling of the High fiequency Behavior of Vacuum Interrupters and Comparision with Measured Transients in Power Systems. XVIIth International Symposium on Discharges and Electrical Insulation in Vacuum, Berkeley, 1996, p. 323-331.
[4] IEEE Working Group 3.4.11: Modeling of metal oxide surge arresters. IEEE Trans. on PWRD 7, n. 1, 1992, p. 302-309.

[5] Popov M., Acha E.: Overvoltages due to switching off an unloaded transforme with a vacuum circuit breaker. IEEE Trans. on Power Delivery 14, n.4, 1999 , p. $317-1322$

[6] Popov M., van der Sluis L.: Improved calculations for no-load transformer switching surges. IEEE Trans. on Power Delivery 16, n.3, 2001. p. 401-408.

[7] Wong S.M., Snider L.A., Loi E.W.: Overvoltages and reignition behavior of vacuum circuit breaker. Int. Conf. on Power Systems Transients IPST'2003, 28 Sept.-2 Oct. 2003, New Orleans (USA), paper 14a.3.

[8] Wróblewski Z.: Badania i symulacja cyfrowa wybranych właściwości łączników próżniowych. PAN: Komitet Elektrotechniki, Seria Wydaw.: Postępy Techniki Wysokich Napięć, t. 25, Ofic. Wydaw. Pol. Wrocławskiej, 2005.

[9] Ograniczniki przepięć z tlenków metali typu POLIM - D. ABB Power Distribution, Wyd. 08.2011 (strona internetowa: www.abb.pl).

\section{Mgr inż. Piotr Pająk}

e-mail: ppajak@agh.edu.pl

Absolwent Wydziału Elektrotechniki, Automatyk Informatyki i Elektroniki Akademii GórniczoHutniczej w Krakowie. Pracuje w Katedrze Elektrotechniki i Elektroenergetyki AGH na stanowisku asystenta. Interesuje się stanam nieustalonymi w systemach elektroenergetycznych, ochrona przepiecciowa oraz przepięciami w układach elektroenergetycznych.

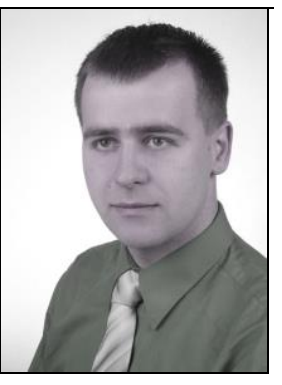

